\title{
Good news!
}

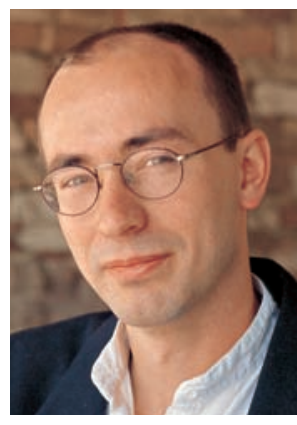

Dr. med. Dieter Schmid, Redaktionsleitung

Only bad news is good news! Warum eigentlich? Warum können Journalisten schlechte Nachrichten nicht einfach für sich behalten und sich auf positive Dinge konzentrieren? Der Grund leuchtet ein: Wer etwas bewegen möchte, muss über Missstände aufklären - in der Hoffnung, dass Menschen aus Fehlern lernen und Probleme gelöst werden. Ein Beispiel: Unicef berichtet, dass die weltweite Sterblichkeitsrate bei Kindern unter fünf Jahren seit 1990 von 93 pro 1.000 auf jetzt 63 pro 1.000 gesunken ist. Fast 30 Prozent weniger tote Babys! Ist das nicht eine gute Nachricht? Einerseits ja - andererseits bedeutet dies, dass nach wie vor pro Jahr 9,2 Millionen Kinder vor ihrem fünften Geburtstag sterben. Wer sich da auf die „good news“" konzentriert, riskiert, dass sich Leser zurücklehnen und sagen: $\mathrm{Na}$, dann ist ja alles in Ordnung! Das ist der Grund, warum auch wir bei Via medici uns nie darauf beschränken, nur die schönen Seiten des Arztberufs darzustellen. In diesem Heft berichten wir z. B. darüber, dass in den USA der Druck des Justizapparats auf Ärzte zunimmt, bei Hinrichtungen zu assistieren. Damit sollen sie den „humanen“ Verlauf der Tötungen gewährleisten (S. 34).

Und doch: Wo gute Nachrichten sind, soll man sie nicht verschweigen. Diese Via medici ist voll davon! Beispiele gefällig? In unserem Artikel „Karrierestart in der Schweiz“ (S. 8) berichten wir von prima Berufsperspektiven in einem Land, in dem die Löhne höher, die Ausbildung besser und die Hierarchien flacher sind. Zudem kann man sich dort in seiner Muttersprache unterhalten (... mit Einschränkungen). Im Artikel „Kreuze fürs Leben“ erklären wir Ihnen, dass auch MC-Prüfungen ihre positiven Seiten haben und dass man sie gut bewältigen kann, wenn man bei der Vorbereitung einige wichtige Regeln beherzigt (S. 16). Und auch dass der Heidelberger Krebsforscher Harald zur Hausen dieses Jahr den Nobelpreis für Medizin bekommen hat, ist eine gute Nachricht. Weniger deswegen, weil damit zum ersten Mal seit neun Jahren wieder ein Deutscher diese Auszeichnung ergattert hat, sondern weil mit zur Hausen ein Querdenker ausgezeichnet wird, der lange gegen Anfeindungen kämpfen musste. Auf S. 58 finden Sie ein Interview mit dem Laureaten.

Und nicht zuletzt: In den deutschen Uni- und Lehrkliniken vollzieht sich derzeit ein erstaunlicher Sinneswandel. Immer mehr Häuser zahlen ihren PJlern Aufwandsentschädigungen (S. 64). Zwar nicht aus Menschenfreundlichkeit oder weil es auf Weihnachten zugeht, sondern weil der Kampf um guten Nachwuchs immer härter wird. Aber das wäre ja auch vielleicht zu viel des Guten ...

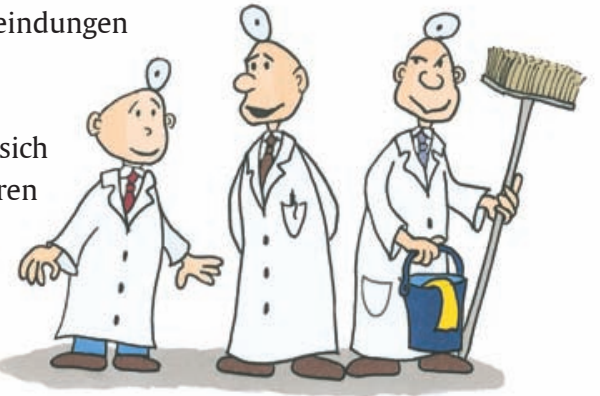

Herzlichst, Ihr

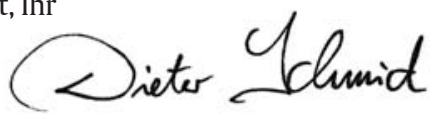

„Zuerst die gute Nachricht: Sie werden für Ihr PJ eine Aufwandsentschädigung erhalten. Dafür werden wir Sie deutlich stärker in den Stationsablauf einbinden ....

\section{ONLINE-UMFRAGE}

\section{Bereit für den Notfall oder Angst vor dem Reinfall?}

In „Das erste Mal: Erstversorgung eines Unfallopfers“ (S. 24) berichtet PJlerin Anika Winkel von einer Situation, in der sie plötzlich aus heiterem Himmel einen Menschen vor dem Verbluten retten musste. Für viele Medizinstudenten ist dies das Angstszenario schlechthin: Was tun, wenn die Frau, die in der U-Bahn neben einem sitzt, auf einmal ohnmächtig wird oder im Restaurant der ältere Herr am Nachbartisch plötzlich keine Luft mehr bekommt? Fühlen Sie sich bestens für solche Situationen gewappnet? Oder haben Sie jetzt schon die leise Vorahnung, dass Ihnen im Ernstfall die wichtigsten Handgriffe nicht mehr einfallen werden, weil in Ihrem Kopf zu viel Detailwissen herumspukt?

\section{- Fühlen Sie sich durch Ihr Studium gut auf Notfälle vorbereitet?}

Stimmen Sie ab und sagen Sie Ihre Meinung unter: www.thieme.de/viamedici/aktuelles aktion/miniumfrage5_08.html
- Ergebnis der Umfrage in Via medici 4.08: Wir fragten, ob Sie Vorlesungen heutzutage für verzichtbar halten. Knapp 63 Prozent der Teilnehmer gehen auch heute noch gern in den Hörsaal. Nur 30 Prozent hielten Vorlesungen für überflüssig. Ein Kritiker meint: „Oft geht man nur fürs schlechte Gewissen hin, für die Klausur lerne ich eh nur mit Büchern. “ Ein Befürworter kontert: „Menschen sind immer noch die besten Lehrer. Ein Dozent präsentiert das Wissen besser als jedes Lehrbuch." Mehr Kommentare unter: .../aktuelles/aktion/miniumfrage4_08.html 